Author's draft of review published in Sociological Review February 2012， 60(1): 180-182

\title{
Tales from Facebook
}

Daniel Miller. Polity Press, Cambridge, 2011, £14.99, 218pp.

In the face of the recent dramatic rise in usage of social networking sites, and in particular Facebook, popular commentary has displayed an urge to generalize about what it all means. Social networking sites have in themselves become news, as the focus for a plethora of stories concerned about their effects on communities and families, their potential dangerous consequences for vulnerable people or their role in uprisings and social activism. The urge to generalise about Facebook, and the instinct to accord it an impetus of its own and ask what it is doing to us is almost irresistible. Miller's book stands in opposition to these tendencies, telling us rich and compelling tales from Facebook without pretending to be able to tell us a singular story about its impact and implications.

Despite the generality of its title and cover blurb, the Facebook that Miller describes is located quite specifically in the Trinidad which has been for many years a focus of his ethnographic attentions. The first part of the book, amounting to over two thirds of its pages, comprises twelve chapters each focusing on an individual's engagement with Facebook (although, for reasons of confidentiality, each individual described is in fact a fictionalised composite). Miller writes in an evocative style, giving rich and lyrical accounts of these individuals and the way in which he comes to know them. He frequently deviates from discussions of Facebook into other aspects of Trinidadian culture, but this is his point: what Facebook is, in Trinidad, stems from heterogenous, complex and specific aspects of Trinidadian culture as manifested through Facebook, rather than being somehow caused by Facebook in itself. 
Miller's key argument is that it is somewhat futile and misguided to set out to study Facebook without looking closely at the contexts in which it is embedded and the uses which its diverse subscribers subsequently make of it. The broad argument is very similar to that made in Miller and Slater's (2000) book about the Internet in Trinidad, in its suggestion that if one wishes to understand the Internet one should should try to work out what a particular culture makes of it. Miller's focus on Trinidad for the current book is opportunistic in that this is the place on which he has most consistently focused in a long ethnographic career to date. This book, in itself, lacks the long term in depth engagement that ethnography demands, and focuses instead on snapshots of lives. Situating this within Miller's long-term focus on Trinidad, however, enables a deeper understanding of the cultural context in which these specific appropriations of Facebook emerge. The focus on Trinidad, and the extent of the deviations from discussion of Facebook has frustrated some online reviwers who were looking for a book that would tell them all about Facebook, and appear to feel cheated that the book is not about the US or UK as they would have expected. Such complaints seem inevitable given the book has been marketed as a relatively popular book about Facebook, but are unfortunate in their lack of engagement with the points Miller wants to make about the importance of looking at the Internet somewhere in particular and the strategic significance of Trinidad as a place to look at culture and technology intertwined.

While the initial twelve portraits celebrate heterogeneity and resist generalization, in the final three chapters of the book Miller begins to draw threads together and to speculate on broad themes which characterise the Trinidadian engagement with Facebook. He has some interesting observations to make on the social bonds formed and strengthened online, which undermine any straightforward notion of social networking sites as either reinforcing or destroying community 
in a traditional sense. He has some intriguing, but frustratingly brief discussions of the individual as, in itself, a site of social networking, of Facebook as a reworking of modern sociality, and of parallels between Facebook and the Kula ring of anthropological fame. These themes would merit a more in-depth development, weaving together the ethnographic richness of the early chapters with a more sustained theoretical treatment.

The book aims to convince us that the secret to understanding what people make of Facebook is in the people themselves and the lives they lead. The format of brief vignettes brings out the diversity in these lives and the Facebook that results for each individual. Unfortunately, however, this format precludes the deeper exploration of Facebook in those lives over time. Miller's book is an important contribution to the still underdeveloped literature on social networking sites, but it far from exhausts the ethnographic possibilities of studying life with Facebook. I would like to see more exploration of how life with Facebook changes over time and how lives are changed in the long term. In Miller's portrayal we see quite restricted snapshots in time for many of the people described and we also see little of the wider media commentary on Facebook and of the economic conditions under which its use is sustained. It would be interesting to explore how far there is a widely shared expectation about what Facebook should be, how much actual experiences over time challenge or confirm that, and what forms an eventual disenchantment with or moving on from social networking sites may take. The timespan in which social networking sites have existed is much shorter than many ethnographic studies have traditionally been and the longer view is of necessity missing from any current study of social networking sites.

Miller's book is intriguing, frustrating and enlightening. Its key strengths are its grounding in Miller's deep knowledge and love of Trinidad, and the depth of its engagement with the 
technology it describes. Miller studies Trinidad by being there, and he studies Facebook by participating there also, and studying the one through the other. This depth of engagement inevitably creates some tensions. Miller tells us how preserving the confidentiality of his informants involved defriending them in Facebook as publication neared, much as this ran counter to his instinct to acknowledge and thank them. Possibly this desire to preserve confidentiality may be the rationale for the lack of visuals in the book, which I found a disappointing omission, and which would have made the book more accessible for an audience not already familiar with the various Facebook features described. This is unfortunate, because this audience probably have most to gain from Miller's depiction of Facebook as life itself, rather than a shallow distraction from life.

Miller, D. and Slater, S. (2000) The Internet: An Ethnographic Approach. Oxford: Berg.

Christine Hine

Department of Sociology

University of Surrey

Guildford, Surrey, GU2 7XH, UK 